\title{
Attributes of Knowledge a transfer scenario
}

\begin{abstract}
The inference of causal ambiguity of the knowledge itself is of primary importance, since the inability to map relationships between a capability and a performance outcome is widely regarded as a commonality, thus, is a direct effect from successful or unsuccessful knowledge transfer. Contemporary literature identifies a perspective definition of what role these relationship concepts play in human cognitive understanding of knowledge and any underpinning relationship characteristics, only that they may exist to interfere with the transfer of knowledge at some obscure point. Most literature assumes this myopic biased view regarding actors interaction surrounding knowledge interpretation, as a consequence, performance differences between groups or businesses are often examined by simply using prescriptive asymmetries linked to knowledge transfer success, but without definition of success. With this view in mind, we will therefore examine various literature perspectives in which both business success and competitive advantage are linked to knowledge transfer.
\end{abstract}

Author: Dr. Michael Fascia

Visiting Professor, Campion Hall, University of Oxford.

Michael.fascia@campion.ox.ac.uk

15 March 2018 
$T$ he position of knowledge in relation to business success remains significant. Knowledge transfer efficiency and effectiveness (Boh, Nguyen, \& Xu, 2013; Brown, 2012; Bruniaux, Cichocka, \& Frydrych, 2016; Dennerlein, Gutounig, Kaiser, Barreiros, \& Rauter, 2015; Szecsenyi, 2014; Tan, Deng, \& Yang, 2014) and the mechanisms of the transfer similarly so. The main reason for this is that throughout the extended route of knowledge, it is the transfer parameters which act as barriers to effective transfer. From a contemporary literature synthesis, it is clear that there is still a theoretical disjunction as to the exact role of knowledge within the transfer process, specifically when linked to business success and competitive advantage (Gebauer, Gustafsson, \& Witell, 2011; Mohanbir Sawhney, 2006; O'Donnell, Gilmore, Carson, \& Cummins, 2002; Michael E. Porter, 1985, 2004; M. E. Porter \& Kramer, 2002; Powell, 2001). This is because a fundamental understanding of knowledge, within practical usage, does not automatically indicate full understanding surrounding the significance of the knowledge content, mode of transfer, barriers or value.

Therefore, knowledge and the practical transfer scenario related to business success form two distinctly different phenomena. On the one hand, propositional clarification regarding any justified beliefs which may interact or depend on anything else, for example experience, for justification.
Whereby, knowledge related to transfer success can be more likely if the sender and receiver are internal to the same experiential boundary or share a superordinate identity (Buthelezi \& Mkhize, 2014; Kaczmarek, Kimino, \& Pye, 2012; Kane, 2010). On the other hand, the inferential epistemic dependence or causal relationship, wherein, knowledge has no dependence on the source or recipient for anything.

As such, a dichotomous position entails. Wherein, knowledge transfer participants may attach value to invalidated external knowledge. Understanding this position from a business or organisational success perspective is fundamental. Since without a substantive appreciation as to the significance or importance of the knowledge and knowledge experience from the transfer perspective, no inference of useful knowledge transfer could be observed, recorded or measured.

Parallels to this position can be drawn with an interactive approach to transfer success (Akhavan, Marzieh, \& Mirjafari, 2015; Sheng, Shen-Yao, Thompson, \& Yuh-Feng, 2013). Whereby, business knowledge, both structural and cultural, may be interpreted as sub systems of interactive knowledge systems, which themselves form regulated sub communities of practice and routines.

Knowledge transfer from this business success perspective therefore may be identifiable as a valuable metric of organisational effectiveness, based on the 
efficiency of the perceived transfer mechanism, process and routines. Consequently, any business or organisation will have an objective in capturing this knowledge and turning it into an effectual tool to obtain competitive advantage.

\section{KNOWLEDGE BASED THEORY}

Since the knowledge-based theory of the firm is the basis of mainstream management literature perspective on knowledge transfer and its linkage to competitive advantage, it is worth clarifying the knowledge-based theory of the firm in some more detail. This is important because, before any knowledge transfer can take place, in the context of an organisational structure, a definitive structure must exist and exhibit boundaries and parameters in which the transfer will take place, be verified, and become useful to underpin success. Thus, an overview of associated management literature clarifies the following primary identifiers of precipitated framework underpinning.

Bhatt, (2001) conclude that organisational knowledge management is a necessary process of knowledge creation, validation, presentation, distribution and application. In aligning this view of enhancement and value to knowledge transfer management (Holm, 2001) suggests getting the right information to the right people at the right time, helping people create knowledge and sharing and acting on information, is a good measurement of efficient

organisational knowledge management in practice. In addition (Horwitch and Armacost,, 2002) conclude that any knowledge management should ensure the creation, extraction, transformation and storage of the correct knowledge and information in order to design better policy, modify action and deliver results. Thus, it is easy to conclude that is that there is a general acknowledgement in achieving competitive advantage by corrective management practices to ensure success. Following on from this, one of the most widely cited articles proposing the knowledge-based view of the firm is from (Nahapiet and Ghoshal, 1998).

In this, research, they define and identify intellectual capital to be the sum of all knowledge a firm utilises for competitive advantage and consists of the three main components: human capital, organisational capital, and social capital. (See Nahapiet and Ghoshal, 1998; Seetharaman et al., 2004; Subramaniam and Youndt, 2005). From this perspective, the combined view of the literature is to parallel the relationship between social and intellectual capital underpinned by a collective view of standardised success. Thus, there are distinct assumptions within the theory, in that, large firms can and do provide resources for social action by providing institutional and subsequent dense networks of social capital, and thus facilitate the development and creation of intellectual capital all linked to knowledge transfer and competitive advantage.

Work by (Hargadon and Fanelli, 2002) define this in greater detail, but go on to explain that whilst knowledge is, in itself critical for commercial success, at the same time it is difficult to define and measure, critically at the organisational level. From these observations, many authors and theorists can therefore conclude that a firm's primary resource function is to link this knowledge into a useful and purposeful tool to assist with competitive advantage. (Kogut and Zander 1992; Nonaka 1994; Grant and 
Baden-Fuller 1995; Zander and Kogut 1995; Conner and Prahalad 1996; Grant 1996a; Kogut and Zander 1996; Spender 1996; Kusunoki et al. 1998; Nahapiet and Ghoshal 1998).To elaborate along this line of reasoning, the following sections will analyse existing literature by scrutinising disparate knowledge outcomes within a theoretical framework whose point of departure is an underpinning of businesses success and competitive advantage.

\section{COMPETITIVE ADVANTAGE}

To elaborate the fundamental importance of knowledge from the previously discussed perspective, Porter's competitive advantage model (Porter, 1985) explains that this very competitive approach is about taking offensive or defensive action to create, as a business, a defendable position in order to cope with competitive forces. This perhaps suggests or even assumes that above average knowledge transfer or management performance of an organisation will offer deliverable and sustained competitive advantage to achieve and maintain success. Clearly, these goals and objectives would be useful to any type of business or organisation as it presents a very practical and focused in achieving business success and competitive advantage.

Linking this focused view to knowledge transfer, Alavi and Leidner, (2001) inform that the 'transfer' process of this organisational knowledge involves the full comprehension of both micro and macro level forces and that this combined comprehention will influence knowledge transfer performance. (Nonaka and Takeuchi, 1995) expand on this and state that, "through this process, people can synchronise their physical and mental rhythms and share their experiences', (Nonaka and Takeuchi,1995. ;p127). Elaborating on this further, knowledge transfer, as described by (Argote and Ingram, 2000), is evolutionary inside any business or organisation as it applies cause and effect parameters such as : laws, regulations, norms and values. To identify a focus on the importance of knowledge at micro and macro level, (Alavi and Leidner, 2001) state that the 'knowledge residing within a business clearly involves both people and context'.

However, importantly continue with,' its comprehension depends on people who interpret, organise, plan, develop, execute and use tools to facilitate the phenomena'. Thus, creation of knowledge and importantly the evolution of any transfer tools both need to be understood from the perspective of all the participating actors and stakeholders. Krogh ,et.al., (2000) conclude that for knowledge transfer to be effective, people need to be persuaded of its usefulness and therefore human cohesion is imperative at all levels of management. Historical analysis by (March and Simon, 1958) acknowledge this position but advise that these heterarchical contextual rules governing knowledge, should all be within the agreed limits of human rationality, and (Brown, 1992) similarly advises that, any multifaceted resources ultimately must be within existing social context.

Thus, to effectively manage this important knowledge and the complexity of the resources needed to exchange it, a series of theoretical models can be identified which not only affix significance to inherent management practices but are also additional 
'structural' features that augment complexity. Understanably, mechanisms, techniques and strategies are all needed to officiate the multifaceted nature of knowledge and knowledge transfer and support the subsequent paradigms and complexities needed to orchestrate its usefulness. As such, when identifying knowledge which is linked to competitive advantage, the literature commonly refers to the number of interdependent supporting technologies, routines, individuals, and resources associated to a particular knowledge culture.

\section{KNOWLEDGE TRANSFER CULTURE}

Business structure and culture linked to knowledge transfer are discussed and identified in a comprehensive study by (Fahey and Prusak, 1998), which indicated the importance of actor interaction and also introduced the concept of parameter hierarchy as a possible solution to known knowledge transfer problems. Elaborating on this, (Schein, 1985) discusses implicit assumptions, which can be held by members of a group, and will determine group behaviour in response, both to its environment and importantly to associated knowledge transfer problems.

In addition to this point of view, (Taifel and turner 1979) discuss the group perspective and assign its relativeness to the individual by elaborating and discussing social identity and knowledge as a single resource factor. They continue by stating that individuals gain this social identity from the knowledge groups from which they belong, which does validate the previous discussion on competitive advantage evolution.
This group interaction is also identified as a significant factor relating to knowledge importance for the individual by (Webber 2001), who states that cultural experiences are essential for people to gain information or knowledge. This view is concurred by (Trompenaars and Hampden-Turner 1997), and (House et al. 2004) who conclude that within the knowledge transfer scenario, the understanding of social identity and cultural significances in relation to a perceived problem or problematic area is an important factor on the success rate of the transfer.

In discussing business culture related knowledge transfer in more detail, (Goh, 2002) advises, for culture to contribute to knowledge transfer success, any culture must have a strong set of core values and norms that will encourage the active participation of any group member and thus reciprocate knowledge transfer within the group. It is easy to understand from this view that at its core, culture, in this case business culture, consists of a set of values and beliefs that are embedded tacit preferences about what the group understand as the value of their knowledge interaction.

Understandably, identification of this group-culture interaction is beneficial to business success and competitive advantage, as (Winter, 1987) points out, the more culturally and socially complex the knowledge, the more difficult it is for competitors to imitate. Clearly a very advantageous position for any business.

However (Cummings and Teng, 2003) note that significant disagreement or mistakes between the group or cultural actors involved with the knowledge transfer process, indicate that new knowledge, if viewed as problematic, will not be accepted or internalised in a 
useful manner. Additionally, (Castro and Neira, 2005) indicate that within associated groups, with a business culture of regularly sending and receiving knowledge within an organisational surrounding, these actors actually favour the transfer of tacit and embedded knowledge, contradicting the popular view that tacit knowledge is 'problematic' and difficult to transfer.

Previous research by (Basu, 1998) explains that there is much debate in current literature about the problems related to knowledge transfer within businesses who adopt a cultural view, in terms of whether their underpinning cultural motives are economic, (to overcome disadvantage and/or improve their financial prospects), social (to improve their social status) or related to historical factors. Additionally, from the perspective of group culture commonality, (Light, 2003), asserts that many business leaders and managers acknowledge the use of cultural backgrounds in determining a problematic area for investigation and problem solving. Light continues that there is a need for leaders to understand the ways in which cultural belief systems influence business decision-making paradigms and approaches, but concludes that, as yet this process is not fully understood.

In contrast to this, (Boyer, 2001; Atran, 2002; Atran and Norenzayan,

2004) argue that culture is no more than a by-product of other cognitive structures, which are themselves experiential adaptations. Additionally, (Whitehouse, 2004; Kirkpatrick, 2005 ) argue that cultural beliefs may be related to religious beliefs and simply evolved as part of the human mental architecture because they were adaptive in one or more ways.
Therefore, understanding of these cultural interactions related to business success are substantial and are important considerations for sustained competitive advantage. Szulanski, (1996) advises, in a very simple way, that close relationships and good reputations increase the potential for successful knowledge transfer. This somewhat generic view by Szulanski is underlined in more relevant detail by (Moore and Habel 1982) who identify that in relation to knowledge, different kinds of experiences and practices are generally accepted as though they are universal and applicable to all societies and cultures but will ultimately need a robust vehicle or conduit to assert their effectiveness. This vehicle or mechanism is discussed and expanded on in the next section.

\section{MECHANISMS OF KNOWLEDGE TRANSFER}

A large proportion of knowledge management literature indicates that the transfer of knowledge linked to business success or competitive advantage commonly involves either a mechanical, commonly IT-based mechanism (Inkpen and Dinur, 1998), or a personal mechanism (Nonaka and Takeuchi, 1995). Hansen et al. (1999) specifically identify these two categories of transfer mechanisms as codification and personalisation. Codification, in this context, involves the dissemination of some kind of written or drawn documents as a means to transfer knowledge.

Thus, codification is defined as the recording of knowledge using words and texts, and transferring the knowledge through the use of written or electronic documents. The main advantages of codification include easy access (Inkpen and Dinur, 1998), wide dissemination, 
low costs, and good preservation of knowledge. A working manual is a good example of codified knowledge.

The personalisation mechanism in this context involves person-to-person interaction, in the form of personal advice or personal training. It can be defined as the transfer of knowledge through person-to-person interaction, allowing the chance to explain and demonstrate the knowledge directly to the recipient. The main advantages of this personalisation mechanism are its ability to articulate non-codifiable knowledge and enhance in-depth understanding (Hansen et al., 1999; Nonaka and Takeuchi, 1995).

Hislop, (2003) further defines mechanisms of knowledge integration and transfer as Intensive team-based interaction; education and the dissemination and operation of formal documentation. Further, (Roy et al. 1995) describe successful knowledge transfer mechanisms as a process with multiple interactions beginning with knowledge creation and ending with exploitation. At this juncture however, it is important to mention Nahapiet and Ghoshal (1998) who note that any mechanism of knowledge transfer within a business setting is affected by, (a) the opportunity for knowledge transfer and exchange, (b) the expectation that it will be worthwhile to do so for both parties and (c) both parties are in fact motivated to pursue knowledge transfer.

These points from Nahapiet and Ghoshal are important since the focus is on interpretation of not only knowledge, but, what effect the transfer of knowledge may have. Expanding this position (Revilla et al.

2005) comment that the manner in which knowledge is 'packaged and dispatched', has the potential to either enhance or to inhibit the receiver, to act appropriately or to assist in decision making.

\section{CONCLUSION}

The transfer mechanism therefore has the potential to be determined by the interpretation of the knowledge being transferred and can be directly related to analogical transfer and knowledge compilation theory. This is because both analogical transfer and knowledge compilation theory relate to how people organise the understanding of knowledge and produce intelligent behaviour related to the understanding process.

What is very clear form these studies and analysis is that there is a fundamental requirement for understanding the mechanics involved to get 'knowledge' moved to the place where it can be most useful.

To do this however, an underpinning framework must first be understood and introduced to support the flow of knowledge in the most advantageous direction for the business, organisation and actors involved. This problematic dilemma remains the main reason why the number of competing strategies for success remain prominent in this area. 


\section{REFERENCES}

Akhavan, P., Marzieh, B., \& Mirjafari, M. (2015). Identifying the success factors of communities of practice (cops). VINE, 45(2), 198.

Boh, W.F., Nguyen, T.T., \& Xu, Y. (2013). Knowledge transfer across dissimilar cultures. Journal of Knowledge Management, 17(1), 29-46. doi: 10.1108/13673271311300723

Brown, I. (2012). Knowledge transfer and exchange (kte) as a source of empowerment. Journal of Intellectual Disability Research, 56(7-8), 723-723.

Bruniaux, P., Cichocka, A., \& Frydrych, I. (2016). 3d digital methods of clothing creation for disabled people. Fibres and Textiles in Eastern Europe, 24(5), 125-131. doi:

10.5604/12303666.1215537

Buthelezi, M., \& Mkhize, P. (2014, 2014/11//

Nov 2014). Factors influencing quality of knowledge shared in software development community of practice, Kidmore End.

Dennerlein, S., Gutounig, R., Kaiser, R., Barreiros, C., \& Rauter, R. (2015, 2015/09//

Sep 2015). Knowledge strategies in organisations: A case for the barcamp format, Kidmore End.

Gebauer, H., Gustafsson, A., \& Witell, L. (2011). Competitive advantage through service differentiation by manufacturing companies. Journal of Business Research, 64(12), 1270-1280. doi: 10.1016/j.jbusres.2011.01.015

Kaczmarek, S., Kimino, S., \& Pye, A. (2012). Board task-related faultlines and firm performance: A decade of evidence. Corporate Governance (Oxford), 20(4), 337-351. doi: 10.1111/j.14678683.2011.00895.x

Kane, A.A. (2010). Unlocking knowledge transfer potential: Knowledge demonstrability and superordinate social identity. Organization
Science, 21(3), 643-660,799.

Mohanbir Sawhney, R.C.W.I.A. (2006). The 12 different ways for companies to innovate. MIT Sloan Management Review, 47(3), 7581.

O'Donnell, A., Gilmore, A., Carson, D., \& Cummins, D. (2002). Competitive advantage in small to mediumsized enterprises. Journal of Strategic Marketing, 10(3), 205-223. doi: 10.1080/09652540210151388

Porter, M.E. (1985). Competitive advantage: Free Press.

Porter, M.E. (2004). Competitive advantage : Creating and sustaining superior performance (Export ed. ed.). New York ; London: Free Press.

Porter, M.E., \& Kramer, M.R. (2002). The competitive advantage of corporate philanthropy. Harvard business review, 80(12), 56-68, 133.

Powell, T.C. (2001). Competitive advantage: Logical and philosophical considerations. Strategic Management Journal, 22(9), 875-888. doi: 10.1002/smj.173

Sheng, M.L., Shen-Yao, C., Thompson, T., \& YuhFeng, L. (2013). Knowledge barriers, knowledge transfer, and innovation competitive advantage in healthcare settings. Management Decision, 51(3), 461478.

doi:

http://dx.doi.org/10.1108/002517413 11309607

Szecsenyi, J. (2014). Knowledge transfer and implementation. [Wissenstransfer und Implementierung.]. Zeitschrift fur Evidenz, Fortbildung und Qualitat im Gesundheitswesen, 108(5-6), 249-250. doi: 10.1016/j.zefq.2014.06.014

Tan, Q., Deng, H., \& Yang, P. (2014). Knowledge transfer across different domain data with multiple views. Neural Computing \& Applications, 25(1), 15-23. doi: 10.1007/s00521- 013-1432-9 